\title{
Análisis multilateral de la política migratoria en la región: hacia una ciudadanía suramericana
}

Jacques Ramírez Gallegos Universidad de Cuenca (Ecuador)

Iréri Ceja CÁrdenas

FLACSO (Ecuador)

\section{Introducción}

La importancia de las políticas migratorias adquirió mayor notoriedad a nivel global desde finales de la década de los años noventa y cobró fuerza en la primera década del nuevo siglo, cuando se empezaron a institucionalizar y a proliferar espacios de diálogo multilateral en materia de movilidad humana. Sin embargo, en Suramérica estos temas son parte de la agenda desde tiempo atrás en los espacios subregionales existentes como son la Comunidad Andina de Naciones (CAN) y el Mercado Común del Sur (Mercosur).

En efecto, en estos dos espacios los temas migratorios se vienen discutiendo con anterioridad (desde los setenta para el caso de la CAN y desde los noventa para el caso de Mercosur), a partir de una perspectiva donde ha prevalecido la categoría de 'trabajador migrante' a quien se le debía otorgar facilidades para la movilidad dado que esto 
constituye un elemento importante para una empresa de mayor alance y prioridad como son los asuntos comerciales y económicos.

Con el paso del tiempo y la llegada de gobiernos progresistas a la región, a estos espacios multilaterales de integración denominados como 'regionalismo abierto' -que han sido criticados por su mirada unidimensional al proceso migratorio (Stang, 2009), así como por su impronta de favorecer los servicios útiles para los acuerdos comerciales (Ramírez y Estévez 2010)-, se han sumado nuevas formas de integración regional donde prevalecen los aspectos políticos sobre los comerciales, como es la Unión de Naciones Suramericanas (Unasur), creada en 2007.

El objetivo de este artículo es analizar los tres espacios multilaterales CAN, Mercosur y Unasur, leídos en clave migratoria. La tesis que sostenemos es que dependiendo de la mirada que se le da a los procesos integración, estos tienen una diferente visión en el tratamiento de los asuntos migratorios. Por un lado, CAN y Mercosur, desde una mirada económica, entienden la migración como un asunto socio laboral, en el que prevalece la categoría de trabajador migrante. Por otro, Unasur, desde una perspectiva política, entiende la movilidad desde una mirada multidimensional, en la que prevalece la categoría de ciudadano migrante.

A nivel metodológico, el trabajo se basa en una revisión de los diferentes documentos, acuerdos, actas y decisiones que la CAN, Mercosur y Unasur han producido en materia de migración poniendo énfasis sobre todo en tres corpus: El Estatuto Andino de Movilidad Humana (2015), el Acuerdo de Residencia Mercosur (2002) y el Informe Conceptual sobre Ciudanía Sudamericana (2014), así como los diferentes documentos que han salido desde Unasur, sobre todo desde el Grupo de Trabajo de Ciudadanía Suramericana y desde la Secretaría General. 


\section{Comunidad Andina de Naciones}

En 1973 los Países Miembros de la CAN (Bolivia, Colombia, Perú, Ecuador, Venezuela y Chile) firmaron el Convenio Simón Rodríguez de Integración Socio-Laboral, que partía de la premisa de que el desarrollo de los pueblos andinos se podía fortalecer mediante la activa participación de los trabajadores y los empleadores en el proceso de integración subregional. En su Artículo 3 indicaba que los gobiernos tenían que conceder atención prioritaria, entre otros aspectos, “al establecimiento de un régimen que facilite la movilidad de mano de obra en la subregión"; y, en el Artículo 4, se acordó "procurar la adopción de normas básicas de protección de los trabajadores migrantes”. Todo esto con el fin de mejorar las condiciones de vida y de trabajo en los países del Grupo Andino. Este convenio fue la base para la futura elaboración de la Decisión 116, Instrumento Andino de Migración Laboral aprobada en 1977, la cual otorgaba preferencias a los trabajadores migrantes provenientes de los países andinos. Algunos de sus artículos y disposiciones merecen ser resaltados:

- Los Países Miembros no obstaculizarán la entrada o salida de trabajadores migrantes (Artículo 4).

- Las oficinas de migración laboral (dependencias de los Ministerios de Trabajo de cada uno de los países) ejecutarán la política migratoria laboral de su respectivo país (Artículo 7a).

- No podrá haber discriminación alguna en el empleo de los trabajadores migrantes en razón de sexo, raza, religión o nacionalidad. El trabajador migrante y su familia tendrán los mismos derechos que los nacionales en lo que respecta a educación, vivienda, salud y seguridad social (Artículos 13 y 14).

- Los Países Miembros adoptarán previsiones tendientes a facilitar la regularización de la situación de los indocumentados. El país de inmigración concederá documentos que autoricen la permanencia y las actividades en su territorio a los trabajadores migrantes indocumentados. $\mathrm{El}$ indocumentado que se 
presenta en demanda de documentación a las oficinas correspondientes no podrá ser expulsado durante el lapso que dure su trámite y podrá continuar trabajando (Artículos 27, 28, 29). Como se observa, no solo se planteaba un trato igualitario y no discriminatorio a todos los trabajadores migrantes pertenecientes a la región andina, quienes tenían preferencia con respecto a otros extranjeros, sino que también se daba facilidades de entrada, de salida y de permanencia; pero sobre todo es digno de rescatar que los asuntos concernientes a la migración laboral quedaban en manos de los ministerios del trabajo, a través de las oficinas de migración laboral y no de los ministerios del interior, como sucede actualmente en la mayoría de los países. Además, se establecieron procesos de regularización para aquellos que se encontraban indocumentados ${ }^{1}$.

Dicho acuerdo posteriormente fue remplazado por la Decisión 545 (de junio del 2003), la cual tenía varios elementos que fueron modificados y la volvieron más restringida. En primer lugar, en los considerandos de la 545 se remarcaba que la libre circulación de personas era necesaria para el establecimiento del "mercado común andino". Se indicaba que había que crear las condiciones "para que a la libre circulación de bienes se añada la libre circulación de servicios, capitales y personas en la subregión".

En segundo lugar, se indicaba que el objeto de dicho instrumento era establecer normas para la progresiva y gradual libre circulación y permanencia de personas andinas con fines laborales bajo relación de dependencia. De esta manera cambia la noción de trabajador migrante: si la decisión 116 lo definía como "todo nacional de un País Miembro que se traslade al territorio de otro País Miembro con el objeto de prestar servicios personales subordinados”, en la Decisión 545 se define como "el nacional de un País Miembro que se traslada a otro País Miembro con fines laborales bajo relación de dependencia, sea de

1 Según Stuhldreher (2006) "aunque la voluntad política apuntaba a enfocar la movilidad de los trabajadores a través de la homogeneización de las reglas vigentes y la generalización del principio general de igualdad de trato, el instrumento 116 no se condijo con las condiciones económicas, sociales y políticas existentes, lo que determinó su inaplicabilidad”. 
forma temporal o permanente" ${ }^{2}$. De esta manera la nueva normativa hablaba específicamente de trabajadores en relación de dependencia, excluyendo a todas las otras categorías existentes.

Por otro lado, se indicaba que quedaban excluidos de dicho acuerdo, "las personas que trabajan en la administración pública y aquellas actividades contrarias a la moral, a la preservación del orden público, a la vida y a la salud de las personas, y a los intereses esenciales de la seguridad nacional" (Artículo 2). Como se ve, cambia el espíritu de la libre circulación de personas en la subregión no solo porque esta se entiende como un mecanismo necesario para la implementación de un mercado común andino; es decir, prevalecen los asuntos comerciales, sino también porque se limita a trabajadores en una sola categoría (en relación de dependencia), empiezan a surgir elementos discriminatorios y subjetivos (actividades contrarias a la moral, a la salud, a la vida) y se implantan las miradas securitistas y de control. Sobre este último aspecto cabe indicar que la categoría de trabajador migrante indocumentado y todo lo articulado sobre este tema que estipulaba la decisión 116 fueron eliminados ${ }^{3}$.

Para aquellos trabajadores migrantes bajo relación de dependencia que pueden beneficiarse de esta decisión, se les otorga igualdad de trato que los nacionales, derecho a sindicalización, a negociación colectiva, acceso a sistemas de seguridad; y se amplía la libre movilidad para su familia que incluye tanto "la pareja como a los hijos menores de edad, a los mayores solteros en condición de discapacidad y a sus ascendientes y dependientes".

Esto queda ratificado y reforzado en la Decisión 583, "Instrumento Andino de Seguridad Social”, en la cual se enfatiza la importancia de

2 Mientras en la 116 se establecieron tres categorías: trabajador calificado, fronterizo y temporal; en la 545 se habla de trabajador con desplazamiento individual, trabajador de empresa, temporal y fronterizo.

3 En la Decisión 545 se indica -en la transitoria cuarta- que los Países Miembros adoptarán previsiones tendientes a facilitar la regularización de la situación migratoria de los trabajadores nacionales andinos que se encuentran en situación irregular que hayan migrado con anterioridad a la vigencia de dicha decisión. 
garantizar los derechos sociales a los migrantes laborales a nivel andino, así como a sus beneficiarios, quienes tendrán los mismos derechos y obligaciones en materia de seguridad social que los nacionales (Artículo 5); es decir, igualdad de trato.

Algo que es necesario visualizar es que la Decisión 583 introduce la categoría de "migrante laboral" para referirse a "toda persona que se haya trasladado del territorio de un País Miembro a otro, independientemente de su nacionalidad o de su condición de trabajador dependiente o independiente". Esta definición es más abarcadora que la señalada en la 545 , ya que no contempla el requisito de dependencia.

Finalmente, la Decisión 584, "Instrumento Andino de Seguridad y Salud en el Trabajo", introduce la categoría de "trabajo decente": el cual debe garantizar, entre otras cosas, la protección de la seguridad y la salud en el ámbito laboral. Se establecen una serie de políticas de prevención de riesgos laborales (Artículos 4-10) y una política de gestión de seguridad y salud en los centros de trabajo (Artículos 11-17). También se establecen una serie de obligaciones para los empleadores.

En resumen, desde la CAN se han elaborado decisiones en materia migratoria que condujeron al Consejo de Presidentes a inicios del siglo XXI a manifestar la importancia de la "libre circulación de personas" como un objetivo que sería implementado de manera gradual. En efecto, si revisamos las decisiones de la CAN (que tienen rango superior a las legislaciones nacionales $)^{4}$, se observa que la mayoría se efectuaron en el primer lustro del nuevo siglo:

4 Las decisiones y las normas jurídicas aprobadas en el marco de la CAN no necesitan ser ratificadas por el órgano legislativo de cada País Miembro ya que son de carácter supranacional. Y, cuando hay contradicciones con las normas legales nacionales, prevalece la decisión de la CAN. Para un análisis detallado ver RAE -Jurisprudencia (2010). 
Tabla 1. Decisiones de la CAN en materia migratoria

\begin{tabular}{|l|c|c|}
\hline \multicolumn{1}{|l|}{ Temas tratados en las decisiones vinculadas con migración } & Decisión & Año \\
\hline Tarjeta Andina de Migración & 397 & 1996 \\
\hline Zonas de Integración Fronteriza en la Comunidad Andina & 501 & 2001 \\
\hline $\begin{array}{l}\text { Centros Binacionales de Atención en Frontera en la } \\
\text { Comunidad Andina }\end{array}$ & 502 & 2001 \\
\hline Reconocimiento de documentos nacionales de identificación & 503 & 2001 \\
\hline Creación del Pasaporte Andino & 504 & 2001 \\
\hline $\begin{array}{l}\text { Ventanillas de entrada en aeropuertos para nacionales y } \\
\text { extranjeros residentes en los Países Miembros }\end{array}$ & 526 & 2002 \\
\hline Instrumento Andino de Migración Laboral & 545 & 2003 \\
\hline $\begin{array}{l}\text { Mecanismo Andino de Cooperación en Materia de Asistencia } \\
\text { y Protección Consular y Asuntos Migratorios }\end{array}$ & 548 & 2003 \\
\hline Instrumento Andino de Seguridad Social & 583 & 2004 \\
\hline Instrumento Andino de Seguridad y Salud en el Trabajo & 584 & 2004 \\
\hline Estatuto Andino de Movilidad Humana & 1343 & 2015 \\
\hline
\end{tabular}

Fuente: Comunidad Andina de Naciones, elaboración propia.

A esta normativa hay que sumarle el surgimiento de diferentes espacios y comités dentro de la CAN que se han creado para tratar el tema migratorio tales como: Comités Andinos de Autoridades de Migración (CAAM, 1994), el Subcomité de Autoridades de Migración Laboral (2004), el Comité Andino de Expertos en Estadísticas Migratorias, el Programa Migración y Trabajo (2008); y el Foro Andino de Migraciones (reemplazó al CAAM) que inició en Quito en 2008 y cuyo principal resultado fue la elaboración del Plan Andino de Desarrollo Humano para las migraciones (aún no aprobado) y el reciente Estatuto Andino de Movilidad Humana aprobado por el Parlamento Andino el 2015.

\section{El Estatuto Andino de Movilidad Humana}

Todo este trabajo y las reflexiones realizadas al iniciar el siglo han dado como resultado una nueva Decisión (1343) aprobada por el Parlamento Andino y denominada "Estatuto Andino de Movilidad Humana". Dicho Estatuto fue presentado y discutido en el IV Foro 
Andino de Migraciones celebrado en Bogotá en mayo del 2013, el cual tiene como objetivo "regular las relaciones entre los Estados Miembros de la Comunidad Andina con los ciudadanos andinos en cuanto al ejercicio de los derechos de movilidad humana, permanencia y circulación dentro de la región andina, enfocándose en la protección y garantía de los derechos de las personas, sin discriminación de ninguna naturaleza" (Artículo 1).

$\mathrm{Al}$ respecto vale la pena mencionar algunos detalles. En primer lugar el cambio del término 'migración' por 'movilidad humana's, y la definición con este término de "los procesos concretos que cualquier persona, familia o grupo humano realiza o experimenta para trasladarse a un sitio diferente al de su residencia habitual. Se incluyen los procesos de emigración, inmigración, retorno, solicitud de asilo y protección internacional, desplazamientos internos y reasentamientos". Dicho concepto de movilidad humana ha penetrado en el ámbito internacional suramericano desplazando al concepto de migración.

Por otro lado, los considerandos de dicha Decisión se orientan por el respeto a los derechos humanos de las personas en movilidad, reconociendo varias falencias de los Estados Partes como la no armonización legislativa, la existencia de discriminación a los migrantes (por ejemplo, la exigencia del pasado judicial para tener acceso a ciertos derechos), la dificultad real del ejercicio pleno de los derechos de libre movilidad o del principio de ciudadanía andina. Resulta muy interesante esta autocrítica realizada por los Estados Miembros de la CAN, poco común en este tipo de documentos multilaterales -donde se suelen resaltar las 'buenas prácticas' y no las 'malas'-.

Y, en tercer lugar, el Estatuto vuelve a colocar en la mesa el concepto de "ciudadanía andina”. Desde el Preámbulo se menciona la "reiterada voluntad de los países andinos de cooperar para la conformación y consolidación de la ciudadanía andina y suramericana, por medio de la cual se propenderá por la garantía del trato igualitario para todos los ciudadanos, sin ningún tipo de discriminación". Se define como ciudadano andino a "la persona nacional

5 Concepto que Ecuador incorporó en el 2008 en la Constitución de la República. 
(por nacimiento o por adopción) de uno de los Países Miembros de la Comunidad Andina" (Artículo 2). De esta manera cualquier/toda persona con nacionalidad colombiana, ecuatoriana, peruana o boliviana es ciudadana andina. Inundación

En todo el Estatuto se usa esta categoría de ciudadana y ciudadano andino que busca otorgar derechos (Capítulo 2), se recuerdan los deberes y obligaciones (Capítulo 3), así como las facilidades para la movilidad, circulación y permanencia (Capítulo 4). Si bien no hay una discusión conceptual sobre esta categoría, es empleada desde una perspectiva jurídica (derechos y obligaciones) y se presentan mecanismos para que los miembros de Estados pertenecientes a la CAN usen mecanismos de identificación (pasaporte andino).

En relación a los requisitos para residir, ya sea temporal o permanente, en el estatuto andino se vuelve a colocar la presentación de justificativos que acrediten la solvencia económica (Artículos 41c y 44d), contrario al Acuerdo de Mercosur, (donde también están incluidos los países andinos) que no pide solvencia económica para otorgar residencia temporal, como veremos más adelante.

Pero quizá el tema más grave de dicho estatuto andino es en relación al acceso a la salud para los ciudadanos andinos. El Artículo 14 señala que "los migrantes tendrán derecho a atención médica de urgencias... Las instituciones de salud, sean públicas o privadas, no podrán negarse o limitarse a prestar los servicios de urgencia requeridos a causa de la situación administrativa irregular de la persona" (énfasis propio). Limitar el acceso a servicios de salud solamente en casos de emergencias no solo es un limitante sino un retroceso en cuanto al principio de igualdad de trato establecido en algunas normas internacionales como el Pacto Internacional de Derechos Sociales, Culturales y Económicos, así como en la Convención sobre la protección de los derechos de todos los trabajadores migrantes y de sus familiares, firmados por todos los Países Miembros de la CAN.

La CAN ha visto afectada su intensidad como espacio multilateral sobre todo a partir de tres eventos: la salida de Venezuela en 2006; el mandato de los Presidentes de la región, al iniciar la segunda década de este siglo, de empezar una reingeniería institucional debido 
a la excesiva burocracia ${ }^{6}$; y sobre todo por el surgimiento de Unasur como nuevo espacio de integración regional a finales de la primera década del nuevo siglo.

Si bien se puede resaltar que dentro de la CAN se dieron los primeros pasos, ya en la década de los años setenta, a partir del Convenio Simón Rodríguez, lo que nunca pudo hacer la CAN fue romper con la tríada "trabajo, migración y residencia”. La migración -o para ser más específicos- la migración vinculada a la residencia en el espacio andino, está supeditada a la categoría laboral y la solvencia económica incluso en el reciente Estatuto Andino. Y como vimos, vinculada específicamente a un trabajo formal con relación de dependencia, quedando de esta manera excluidos aquellos trabajadores informales que cruzan fronteras y por supuesto aquellos que no son trabajadores.

\section{Mercosur}

El Mercado Común del Sur (Mercosur) nació en 1991 como una respuesta económica de integración regional bajo el Tratado de Asunción suscrito por Argentina, Brasil, Paraguay y Uruguay. Desde la creación de Mercosur se previó que el Tratado quede abierto para la adhesión de los demás Países Miembros de la ALADI. Por lo que posteriormente se adhirieron Venezuela (2006) y Bolivia (2012) ${ }^{7}$. Además de los Estados Partes, tiene como Estados asociados a Chile, Colombia, Ecuador, Guyana, Surinam y Perú.

Mercosur pretendía lograr una adecuada inserción económica internacional para sus países, considerando que esta debía ser alcanzada

6 A manera de ejemplo, "para el pleno cumplimiento de la Decisión 545 debe aprobarse su reglamento por parte de la SG de la CAN, previa opinión del Consejo Asesor de Ministros de Trabajo y del Comité Andino de Autoridades de Migración, en consulta con el Consejo Andino de Ministros de Relaciones Exteriores. El reglamento continúa en su fase de discusión técnica" (Artola, 2015: 14)

7 Para que Bolivia sea Estado Miembro Pleno falta la ratificación de los parlamentos de Brasil y Paraguay. 
bajo la coordinación de políticas macroeconómicas y la complementación de los diferentes sectores de la economía (Mercosur, 1991), comenzando por la libre circulación de bienes y servicios y la adopción de un arancel externo común.

En efecto, a partir de la década de los noventa, con la aceleración del proceso de mundialización del capitalismo, los Estados se enfrentaron a nuevos reajustes económicos que en algunos casos dieron paso a respuestas regionales. $\mathrm{Al}$ mismo tiempo, en otras latitudes se consolidaban grandes proyectos económicos que "desde arriba" buscaban trazar rutas de desarrollo para América Latina, como el Consenso de Washington -que promovía una serie de reformas para los países en desarrollo-, los antecedentes de lo que posteriormente sería la Organización Mundial del Comercio (OMC) y la Iniciativa para las Américas, proyecto impulsado por el presidente de Estados Unidos, George Bush, que promovía el libre comercio, la inversión extranjera y la reducción de la deuda externa.

A mediados de la década de los años noventa del siglo pasado, a partir del Protocolo de Ouro Preto (1994), se redefinió el Mercosur como una unión aduanera, con zonas de preferencia arancelaria, ratificando, de esta manera, los elementos comerciales como el centro de los procesos de integración mercosureña. Así mismo se desarrolla su institucionalidad, donde los temas sociales solo son incorporados como subsidiarios de los económicos.

Sin embargo, la crisis económica de finales del siglo XX en la región -particularmente en Argentina y Uruguay-, las alternancias de Gobierno, el rechazo popular masivo a los intentos de Estados Unidos de imponer el ALCA, así como el papel que la República Bolivariana de Venezuela, comenzó a jugar en la región y el estancamiento en varios de los postulados de Mercosur en 1998 posibilitó el replanteamiento de dicho mercado común ya no solo con miras a lo económico, sino también con injerencia en el ámbito político y social (Bizzozero, 2011). Un ejemplo de ello es la Declaración Sociolaboral del Mercosur emitida en 1998 y que, entre otras cosas, postulaba lo siguiente:

1. Todo trabajador tiene garantizada la igualdad efectiva de derechos, trato y oportunidades en el empleo y ocupación, sin 
distinción o exclusión en razón de raza, origen nacional, color, sexo u orientación sexual, edad, credo, opinión política o sindical, ideología, posición económica o cualquier otra condición social o familiar, en conformidad con las disposiciones legales vigentes.

2. Los Estados Parte se comprometen a garantizar, a través de la normativa y prácticas laborales, la igualdad de trato y oportunidades entre mujeres y hombres.

3. Todo trabajador migrante, independientemente de su nacionalidad, tiene derecho a ayuda, información, protección e igualdad de derechos y condiciones de trabajo reconocidos a los nacionales del país en el que estuviere ejerciendo sus actividades, de conformidad con las reglamentaciones profesionales de cada país (Mercosur, 1998).

Esta inclusión de lo social en la agenda del Mercosur se vuelve más evidente a partir del año 2000, con medidas sociales que trascienden lo laboral, desarrollando toda una estructura institucional con el objetivo de profundizar la dimensión social en el Mercosur.

Desde sus orígenes, el Mercosur fue concebido como un espacio de "naturaleza intergubernamental, no un régimen basado en la idea de supranacionalidad" (Modolo, 2012); lo que implica que las decisiones del pleno deben ser tomadas por consenso por los miembros pero no necesariamente ingresan en la agenda inmediata de cada país soberano. A diferencia de la CAN, al no existir una jurisdicción comunitaria que organice el espíritu legal de los acuerdos, estos pueden tener diferentes alcances e interpretaciones -de acuerdo al cuerpo legal de cada país- a las que originalmente inspiraron su creación.

De esta manera, al iniciar el nuevo siglo, Mercosur amplió su espectro de intervención pensando ya no solo temas económicos, sino también políticos y sociales, colocando nociones como ciudadanía Mercosureña (Decisión 64), igualdad de derechos, acceso y libre movilidad como un elemento necesario para la integración regional.

Tal como ocurrió con la CAN, fue a partir del vínculo entre los temas comerciales y laborales que se introdujeron posteriormente los asuntos migratorios con la creación, en 1995, del subgrupo de Trabajo 
de Asuntos Laborales, Empleo y Seguridad Social (SGT10). A finales de esa década (1998) se firmó la ya nombrada Declaración Sociolaboral del Mercosur.

Si bien el poner trato igualitario para nacionales y mercosureños constituyó un paso importante, fue a inicios del nuevo siglo -con la firma de la Carta de Buenos Aires sobre Compromiso Social en el 2000- que se expresó la necesidad de profundizar la dimensión social en el proceso de integración mercosureño, que entre otras medidas hacían alusión al tema migratorio (Modolo, 2012). De esta manera se introdujeron los temas sociales como complemento a los temas económicos y se empezaron a tratar los temas migratorios. El avance más notorio en este espacio fue la aprobación en 2002 del Acuerdo sobre Residencia para Nacionales de los Estados Partes del Mercosur y asociados y la aprobación del Plan de Acción para el Estatuto de la Ciudadanía Mercosur en el 2010 que permitió, con trámites relativamente sencillos, residir en algún País Miembro y un mayor acercamiento al concepto de ciudadanía suramericana.

\section{El Acuerdo de Residencia de Mercosur}

A partir del año 2000 se produjo una ruptura en la óptica de control que caracterizó los primeros años a las iniciativas llevadas a cabo por el Grupo Especializado Migratorio -instancia que precedió al Foro Especializado Migratorio-, que se centraba en acciones en zonas fronterizas para regular la entrada y salida de las poblaciones de estos espacios. En ese año se firmó el Acuerdo sobre Exención de Traducción de Documentos para Trámites Migratorios, destinado a eximir de la entrega de traducciones de los documentos solicitados como requisitos para realizar trámites migratorios; de manera específica, del certificado de carencia de antecedentes penales (Alonso, 2012).

Posteriormente, en 2002, este cambio que empezaba a cuajar se puso de manifiesto en la negociación del Acuerdo sobre Residencia del Mercosur, Bolivia y Chile, el que además de suscitar una mayor conciencia acerca de que el tema migratorio representa un elemento 
fundamental para avanzar en la integración regional, permitió visibilizar su especificidad y por ende la necesidad de crear una instancia especializada en su tratamiento, modificando así la estructura interna de la Reunión de Ministros del Interior. Así, en 2003 se reemplazó al Grupo Especializado Migratorio por el Foro Especializado Migratorio, cuyo funcionamiento contempló una comunicación más directa de las negociaciones en este ámbito con la Reunión de Ministros del Interior (Alfonso, 2012).

El Acuerdo de Residencia Mercosur nació con el objetivo de eliminar la situación migratoria de irregularidad de los nacionales de los Estados Partes ${ }^{8}$, y de constituirse en el instrumento que viabilice la implementación de una política de libre movilidad (y libre residencia) que contribuya a consolidar el proceso de integración regional, que como último fin tiene la eventual creación de una ciudadanía suramericana.

En este contexto, el punto de partida del Acuerdo de Residencia es la concepción de un único criterio migratorio que determine la posibilidad de acceder a una visa de residencia temporal o permanente en el territorio que conforma el bloque de Mercosur, que consiste en la acreditación de la nacionalidad del solicitante de uno de los Estados Partes del Mercosur y Asociados. Es decir, los principales beneficiarios son los ciudadanos nacionales de los países de la región. A este criterio, o motivo migratorio, se lo denominó el criterio de "nacionalidad Mercosur" (OIM, 2014).

En esta revisión de algunos de los cambios de visión que se han producido al interior de Mercosur es importante reconocer la incidencia especial que en el tema migratorio han tenido países como Argentina y Brasil, que han impulsado, en diferentes momentos y espacios, la incorporación de un enfoque de derechos, así como el tratamiento de la migración en negociaciones birregionales -de manera específica en aquellas con la Unión Europea-, no solo desde la irregularidad, sino también considerando los aportes de la población en

8 Según F. Agusti (2015), Director de Asuntos Internacionales y Sociales, del Ministerio del Interior y Transporte de Argentina, en la región existían entre 2 y 2.5 millones de personas irregulares. 
movilidad en los países de origen y de recepción. En definitiva, los cambios en el Mercosur, sobre todo en lo que respecta a la migración intrarregional, se han impregnado de las tendencias de los Gobiernos de la región que mantienen discursos más cercanos al Regionalismo Posneoliberal (Sanahuja, 2009) que al Regionalismo Abierto9.

Así, es importante comprender el Acuerdo de Residencia en el marco de un intento de cambio de enfoque de las políticas migratorias regionales que son el resultado contingente de procesos políticos e históricos concretos (Favell, 2000), y a través del cual los Estados convienen herramientas multilaterales para implementar acciones comunes al interior de sus territorios (Modolo, 2012). Acciones comunes necesarias que buscan regularizar los problemas de movilidad intrarregional. Acciones que se lograron concretar en apenas cuatro meses de negociaciones antes de la firma por parte de los Presidentes de Mercosur realizada el 6 de diciembre del 2002 en la ciudad de Brasilia.

En efecto, en una decisión histórica los Países Miembros de este bloque, liderados por Argentina y Brasil, tomaron una decisión fundamental: dejar de pensar que la solución era realizar amnistías periódicas para solucionar el problema de los migrantes intrarregionales y crear un instrumento permanente que permita regularizar a las personas que se mueven de un país a otro dentro del bloque.

Además del propósito central del Acuerdo de Residencia de "solucionar la situación migratoria de los nacionales de los Estados Partes y Asociados", en los considerandos se indican dos temas a resaltar: la reafirmación de "fortalecer y profundizar los procesos de integración así como los fraternales vínculos existentes" y la necesidad de "implementación de una política de libre circulación de personas en la región”.

9 Según la CEPAL (1994), el Regionalismo Abierto es "un proceso de creciente interdependencia económica a nivel regional, impulsado tanto por acuerdos preferenciales de integración como por otras políticas en un contexto de apertura y desreglamentación, con el objeto de aumentar la competitividad de los países de la región y de constituir en lo posible un cimiento para una economía internacional más abierta y transparente”. 
De esta manera se combinan tres elementos centrales como antecedentes del Acuerdo de Residencia: integración -libre movilidad- y regularización. Bajo estas premisas se establecieron las reglas comunes para cumplir con el objetivo de que: "Los nacionales de un Estado Parte que deseen residir en el territorio de otro Estado Parte podrán obtener una residencia legal en este último, de conformidad con los términos del este Acuerdo, mediante la acreditación de su nacionalidad y presentación de requisitos previstos en el Artículo 4 (Artículo 1)".

El Acuerdo habla de dos tipos de residencia: la temporal, que se podrá otorgar hasta por dos años; tiempo después se podrá solicitar la residencia permanente (Artículos 4 y 5). Un elemento a resaltar es que podrán solicitar dicha residencia todos los ciudadanos de Mercosur, "con independencia de la condición migratoria con la que hubieran ingresado al territorio del país de recepción, e implicará la exención del pago de multas u otras sanciones más gravosas" (Artículo 3). Los requisitos establecidos para otorgar la residencia temporal a los peticionarios son los siguientes, como consta en el Artículo 4:

a. Pasaporte válido y vigente o cédula de identidad o certificado de nacionalidad;

b. Partida de nacimiento y comprobación del estado civil y certificado de nacionalización o naturalización cuando fuere el caso;

c. Certificado que acredite la carencia de antecedentes judiciales, penales o policiales en el país de origen o en los que hubiera residido durante los cinco años anteriores a su arribo al país de recepción;

d. Declaración jurada de carencia de antecedentes internacionales penales o policiales;

e. Certificado que acredite la carencia de antecedentes judiciales, penales o policiales en el país de recepción (para los que soliciten regularización);

f. Certificado médico (si fuera exigido por la legislación interna del Estado Parte);

g. Pago de una tasa retributiva de servicios. 
De estos requisitos llama la atención la carga de aquellos vinculados con los temas de seguridad y control. Lo que se busca exclusivamente es que el 'otro' a quien se le piensa otorgar la residencia no haya tenido antecedentes penales, policiales o judiciales; tanto en el pasado (en el país donde residió), como en el país donde solicita la residencia. También se mantiene la posibilidad de pedir certificado médico, requisito anacrónico que afortunadamente muchos de los Estados de la región han dejado de solicitar.

La parte más novedosa de los requisitos es que, a diferencia de lo que sucedió en la CAN, el Acuerdo de Residencia de Mercosur rompe con la ecuación trabajo-migración. Como se observa, no se solicita ningún certificado que acredite actividad laboral en el país donde se quiere residir, lo cual ha sido extremadamente positivo para ampliar las opciones de obtener dicha residencia temporal. Sin embargo, al solicitar la residencia permanente aparece un nuevo requisito: "Acreditación de medios de vida lícitos que permitan la subsistencia del peticionario y su grupo familiar conviviente" Artículo 5d); pero disminuyen los requisitos de seguridad y control.

Una vez que se ha otorgado la residencia, los ciudadanos tienen derecho a entrar, salir, circular y permanecer libremente en el territorio; así como tienen derecho a acceder a cualquier actividad en las mismas condiciones que los nacionales del país de recepción (Artículo 8). De esta manera se otorga igualad de derechos civiles, reunificación familiar, trato igualitario, derecho a transferir remesas y derechos a los hijos (Artículo 9); y se contemplan sanciones a personas que empleen a nacionales de los Estados Partes en condiciones ilegales (Artículo 10). Algo que no se nombra en el Acuerdo son los derechos políticos de las personas a quienes se otorga la residencia. Como ya señalamos, los temas de derechos políticos (sobre todo el sufragio de los extranjeros) quedan excluidos del Acuerdo, con lo que se da por supuesto que se trata de una decisión que toman los Estados de manera unilateral.

Si bien el proceso de implementación del Acuerdo varió de país a país -considerando la demora de Paraguay para ratificarlo en el Parlamento-, algunos empezaron a aplicar de manera unilateral o bilateral como fue el caso de Argentina y Brasil. Posteriormente, los otros Estados Partes y Asociados se fueron sumando. 
Haciendo una breve cronología, el primer país en realizar el depósito de ratificación fue Argentina el 19 de julio del 2004, y años antes incorporó en su norma interna el criterio de "nacionalidad Mercosur". Brasil ratificó el Acuerdo el 18 de octubre del 2005 y lo implementó para Argentina, Paraguay, Uruguay, Chile y Perú; mientras que se encuentra en proceso de internalización con Ecuador.

Uruguay incorporó el Acuerdo el 8 de diciembre de 2005 y lo ratificó el 8 de marzo de 2006. Un aporte interesante en el caso uruguayo es que con la aprobación de la reciente Ley de Residencia, desde el 2014 se otorga la residencia permanente para los ciudadanos mercosureños sin aplicar primero la residencia temporal; es el único país que lo implementa de esta manera y sin costo ${ }^{10}$. Paraguay ratificó el Acuerdo de Residencia el 28 de julio de 2009 y fue el último Estado Parte en ratificarlo.

A la fecha de la firma del Acuerdo de Residencia, en diciembre de 2002, solo Chile y Bolivia eran países asociados al Mercosur. Bolivia incorporó a su legislación interna el Acuerdo sobre Residencia en 2004 y efectuó el depósito del instrumento de ratificación el 11 de abril del 2015.

En Chile, el Acuerdo entró en vigor el 18 de noviembre de 2005; sin embargo, los beneficios no han sido extendidos para los países que se adhirieron posteriormente, como es el caso de Perú, Ecuador y Colombia, y otorgó la visa temporal por un año prorrogable por igual período.

La internalización e implementación por parte de Colombia del Acuerdo de Residencia se ratificó en septiembre del 2012 y aplica para Argentina, Brasil, Bolivia, Perú, Chile, Ecuador, Uruguay, Paraguay y Venezuela. Perú suscribió el Acta de adhesión al Acuerdo el 28 de junio de 2011, junto con Ecuador ${ }^{11}$. Entre tanto, Venezuela no ha suscrito dicho acuerdo pero elaboró un acuerdo ministerial que habilita

10 Vale la pena señalar que Uruguay ha firmado convenios bilaterales con Brasil y Ecuador, el cual permite a los uruguayos en Brasil y Ecuador, y a los brasileños y ecuatorianos en Uruguay, obtener la residencia permanente de manera directa si desean radicarse en estos países.

11 Fue a partir de abril del 2014, una vez que la Asamblea ratificó el Acuerdo, que se empezó a implementar. 
el criterio de nacionalidad Mercosur para ciudadanos argentinos en principio de reciprocidad con dicho país (Resolución número 90 del 28 de marzo de 2011 del Ministerio del Poder Popular para Relaciones Interiores y Justicia).

La aprobación del Acuerdo de Residencia también señalaba la necesidad de armonizar las legislaciones de cada país, algo que no todos han hecho. De todos modos el Acuerdo de Residencia Mercosur, aunque no todos estén aplicando, constituye en la actualidad el principal mecanismo multilateral regional en materia migratoria y ha permitido regularizar a miles de ciudadanos migrantes suramericanos. Según el Alto Comisionado del Mercosur, Florisvaldo Fier, se han otorgado 780.000 residencias Mercosur entre 2002 y 2012. El mayor problema de este Acuerdo es que algunos países han adaptado el mismo según sus criterios nacionales como por ejemplo Chile, que otorga la residencia temporal por un año con posibilidad de prórroga o Colombia, país que no entrega residencias permanentes sino solo por 5 años.

\section{Unasur}

Los intentos de avanzar en los temas de migración desde una entrada de la ciudadanía suramericana han sido retomados e impulsados desde el nuevo espacio regional de integración que es la Unión Suramericana de Naciones (Unasur). Desde su Tratado Constitutivo se señala la importancia de consolidar la identidad suramericana con el fin de alcanzar una ciudadanía regional.

Como es de conocimiento general, la Unasur nació como un proceso de integración de carácter político y de ahí la diferencia con la CAN y Mercosur (analizados anteriormente). Esto no significa que los temas comerciales, de seguridad, infraestructura, ciencia y educación, entre otros, no sean importantes, sino que estos surgen como parte de un diálogo político en el cual hay o puede haber diferentes posturas entre los Estados Miembros, pero se mantiene la idea de que los sujetos de la integración son las personas concebidas como ciudadanos y no como meros factores de producción. Solo visto de esta manera se puede entender por qué se conformó, como veremos más adelante, un Grupo de Trabajo sobre Ciudadanía Suramericana, y no 
sobre trabajadores migrantes o grupo sociolaboral como existió en los otros subespacios analizados.

Como señalan Rojas, Altmanm y Beirute (2012), los temas clave que inhiben a los procesos de integración son de carácter político y estos subsumen a la dimensión económica. Esta particularidad es significativa porque en buena medida se deriva del rol protagónico de los Estados en el proceso que configura un esquema intergubernamental de toma de decisiones.

La formación de la Unión Suramericana de Naciones vino impulsada con los vientos del nuevo siglo de conformar un Regionalismo Posneoliberal. Luego de varias deliberaciones, el 8 de diciembre 2004, en la III Cumbre de Presidentes realizada en el Cuzco-Perú, se firmó finalmente el acta constitutiva de la Unión pensando en la conformación de un espacio de integración geopolítico denominado en aquel entonces como Comunidad Suramericana de Naciones.

Desde sus inicios se planteó que sus miembros fueran todos los Estados de Suramérica, todos como miembros plenos ${ }^{12}$. Años más tarde, en el marco de la I Cumbre Energética Suramericana desarrollada en Venezuela (2007), se acordó cambiar de nombre tal como se conoce hasta nuestros días: Unión de Naciones Suramericanas (Unasur).

Un año después, en la Cumbre Extraordinaria de Jefes y Jefas de Estado de Unasur realizado en Brasilia el 23 de mayo del 2008, se aprobó el Tratado Constitutivo que entró en vigencia el 11 de marzo del 2011. En el Tratado Constitutivo, como ya se indicó, señala la necesidad de consolidar "una identidad suramericana a través del reconocimiento progresivo de derechos a los nacionales de un Estado Miembro residentes en cualquiera de los otros Estados Miembros, con el fin de alcanzar una ciudadanía suramericana" (Artículo 3, literal i).

De igual manera, se indica en el Tratado la necesidad de cooperar en materia de migración "con un enfoque integral, bajo el respeto irrestricto de los derechos humanos y laborales para la regulación migratoria y armonización de políticas" (Artículo 3, literal k). Como se observa, desde los orígenes de Unasur se piensa tratar

12 A diferencia de Mercosur y la CAN que hay Estados Miembros plenos y asociados. 
el tema migratorio no desde el enfoque de la gestión o control migratorio, sino desde un enfoque integral, privilegiando la ciudadanización y los derechos.

\section{El Informe Conceptual de Ciudadanía Suramericana}

La Unión de Naciones Suramericanas, mediante Decisión 8/2012 del Consejo de Jefas y Jefes de Estado, creó el Grupo de Trabajo sobre Ciudadanía Suramericana (GTSC), confiriéndole el mandato de elaborar un informe conceptual que explore las diferentes dimensiones de la ciudadanía suramericana; para lo cual se acordó que el Consejo de Ministras y Ministros de Relaciones Exteriores de la Unasur debería presentar al Consejo de Jefas y Jefes de Estado en el 2014 las propuestas, lineamientos estratégicos y proyectos de acuerdo que sienten las bases de la ciudadanía suramericana.

El GTCS tuvo su primera reunión bajo la Presidencia Pro Tempore (PPT) de Perú, en cuya cita se elaboró una hoja de ruta, un cuadro de principios rectores y una matriz sistematizada de aportes remitidos por los Países Miembros de la Unión. En la VII Reunión Ordinaria de Jefas y Jefes de Estado y de Gobierno, celebrada en Paramaribo, Surinam, el 30 de agosto de 2013, se transfirió la PPT a Surinam y, en ese marco, la República Argentina asumió la Presidencia Pro Témpore (PPT) del Grupo, que convocó a una videoconferencia realizada en octubre de 2013, en la cual se presentó un primer borrador del informe conceptual. Se registró en esa oportunidad la participación de la totalidad de los Países Miembros de la Unión y se consensuó adoptar el texto elaborado por Argentina como documento de referencia para continuar con la elaboración de aportes al mismo.

En diciembre de 2013, el GTCS efectuó su primera reunión presencial en la ciudad de Cartagena de Indias, Colombia, en la que se debatió en detalle el contenido del borrador del informe conceptual. La segunda y tercera reunión presencial del GTCS tuvo lugar en Buenos Aires, 
Argentina, en abril y en junio del 2014, respectivamente. Finalmente, en julio de 2014, se efectuó una videoconferencia del GTCS, en la que el grupo llegó al consenso y aprobó la redacción final del Informe Conceptual, incluyendo los lineamientos estratégicos.

Siguiendo los canales institucionales, el GTCS envió el Informe Conceptual sobre Ciudadanía Suramericana al Consejo de Delegadas y Delegados de Unasur, para su consideración y posterior remisión al Consejo de Cancilleres de la Unión. Finalmente, el 4 de diciembre de 2014, en la ciudad de Guayaquil , Ecuador, el Consejo de Ministras y Ministros de Relaciones Exteriores de Unasur, mediante resolución No. 14/2014, decidió “aprobar el Informe Conceptual elaborado por el Grupo de Trabajo sobre Ciudadanía Suramericana (GTCS) e instruir que sea tomado como base y referencia en el proceso de construcción de la ciudadanía suramericana"; y "encomendar al GTCS la presentación en la próxima reunión ordinaria del Consejo de Jefas y Jefes de Estado y de Gobierno de la Unasur, de las propuestas, proyectos de acuerdo y plan de acción necesarios para poner en práctica los lineamientos estratégicos contenidos en el Informe Conceptual, y de esta manera continuar el proceso de construcción de la ciudadanía suramericana con el apoyo de los Consejos Sectoriales de la Unasur en el ámbito de sus competencias” (Unasur, 2014a).

En dicho informe conceptual se definió que:

La ciudadanía suramericana es la condición jurídica de acceso progresivo a derechos, deberes y obligaciones por parte de los ciudadanos y ciudadanas de la Unasur. Es una ampliación, no sustitutiva, de las ciudadanías nacionales. Asimismo, es la condición de identidad, pertenencia y arraigo a la tierra suramericana, a sus tradiciones y costumbres, a sus culturas diversas, a sus lenguas e idiomas y a sus cosmovisiones, cuyo fundamento primario es la historia compartida de los Países Miembros de la Unasur (Unasur, 2014b:14). 
Esta definición, que se nutre de lo trabajado en los otros procesos subregionales de inferior índole ${ }^{13}$ y que el informe conceptual estipula que tiene que dar nuevos e innovadores pasos ${ }^{14}$, pone dos ejes centrales: por un lado, se plantea reconocer la categoría de ciudadanía suramericana como una categoría jurídico-política (acceso progresivo a derechos y deberes); por otro, como una categoría socio-cultural (identidad, tradiciones, costumbres, cosmovisiones, etcétera).

A partir de recuperar la importancia de la "historia compartida" en la región, esta definición de ciudadanía suramericana, al considerarse como una "ampliación”, admite diferentes niveles de membresías que nos permite entenderla desde la categoría de ciudadanía mixta que hablamos en el primer capítulo. Al reconocer la existencia de nuevos actores políticos desde Unasur se plantea la extensión y transnacionalización de los derechos y deberes de los ciudadanos suramericanos.

Con lo cual lo que hace Unasur es pensar la noción de ciudadanía más allá de la perspectiva formal que implica concebir a la persona en función de sus derechos y obligaciones dentro de una comunidad política tal como lo señaló Marshall (1959), entendiendo que la ciudadanía no tiene que pensarse solamente desde la parte formal, sino también desde la parte sustantiva: no solo hay que preguntarse qué es la ciudadanía, sino cómo ejerzo y practico la misma por fuera del Estado al que pertenezco.

Por otro lado, con la definición que brinda el Informe Conceptual elaborado por Unasur, se entiende también la ciudadanía desde una perspectiva sociocultural, la cual implica pensar a partir de los lazos identitarios que genera el ser parte de una comunidad imaginada ampliada (Anderson, 1993), ser parte de una geografía imaginada (May,

13 "La construcción de la ciudadanía regional tiene expresiones y avances muy concretos y relevantes en los dos principales procesos subregionales de integración, la CAN y el Mercosur, traducido en un proceso de otorgamiento igualitario y de generalización gradual de derechos.” (...) En tanto modelos de integración (Comunidad y Mercado Común) de índole inferior a la Unión, ambos procesos tienen menores alcances que la Unasur (Unión política y económica) (Unasur, 2014b: 9).

14 "El proceso de construcción de una identidad y ciudadanía suramericanas debe ser innovador, e ir más allá de la imprescindible convergencia de los procesos subregionales en la materia" (Unasur, 2014b: 8). 
1999), en este caso suramericana, donde se activa una suerte de identidades múltiples que permiten ejercer una ciudadanía mixta en el lugar de destino visibilizando las diferencias étnicas y culturales.

A su vez, en el Informe Conceptual de Ciudadanía Suramericana se señala el tema de la libre movilidad y residencia como un elemento central para el proceso de integración. Algo que se ratifica en otros documentos, como "Visión Estratégica de Unasur, en la agenda social", donde los Vicecancilleres en noviembre del 2014 propusieron: "avanzar en la profundización de la ciudadanía suramericana, a partir del Informe Conceptual sobre las diferentes dimensiones de la Ciudadanía Suramericana”.

En este contexto, en el documento De la Visión a la Acción (Unasur 2014c), iniciativa presentada por la Secretaria General, se señala expresamente que "las Jefas y Jefes de Estado y de Gobierno de los países de Unasur ofrecen pleno respaldo al avance de la conceptualización y desarrollo de la ciudadanía suramericana que incluye el informe conceptual sobre la misma y sus lineamientos estratégicos" (literal X). En dicho documento ${ }^{15}$ que busca pasar "de la teoría a los hechos" también se señala el respaldo a "la imprescindible convergencia en cuanto a la dimensión migratoria, la homologación de títulos educativos, el fortalecimiento de la red consular suramericana, los acuerdos en materia de seguridad social que acompañen al trabajador en sus desplazamientos y la definición de una política para el apoyo de los migrantes suramericanos por fuera de la región. Así mismo, la creación de un mecanismo que facilite la libre movilidad de los suramericanos en la región como el pasaporte suramericano”.

15 Documento aprobado por parte de los Jefes y Jefas de Estado. Este documento basa sus antecedentes en la Declaración de Jefas y Jefes de Estado y de Gobierno aprobada en Quito el 5 de diciembre de 2014, la cual "adopta los elementos consensuados de la visión estratégica de Unasur sugeridos por los Vicecancilleres en su II Reunión de Santa Cruz de la Sierra el 21 de noviembre de 2014. (...) sostiene que la paz, la democracia y la promoción de los derechos humanos son los principios rectores del proceso de integración regional, impulsados a través de las agendas social, económica, política e institucional". 
Posterior a lo que se proponía y discutía en varios espacios y documentos de la Unión, en septiembre de 2015 tuvo lugar la videoconferencia del Grupo de Trabajo de Ciudadanía Suramericana, convocada por la Presidencia Pro Témpore de la República Oriental del Uruguay. En la sesión se expusieron las propuestas de Ecuador (cinco), Uruguay (tres) y Argentina (una), en atención a los lineamientos estratégicos contemplados en el Informe Conceptual de Ciudadanía Suramericana. En dicha reunión, la Secretaría General ${ }^{16}$ manifestó el especial interés en trabajar conjuntamente con el GTCS, brindando el soporte técnico necesario para el avance de las diversas propuestas presentadas por los Estados y aquellas que pudiera presentar la Secretaría General en el marco de la Ciudadanía Suramericana (Unasur, 2015a).

Este aporte se concretó en la siguiente reunión presencial del GTCS, realizada en Montevideo en noviembre del 2015, donde participaron representantes de 10 países, exceptuando a Guayana y Surinam, donde la Secretaría presentó un análisis detallado de los flujos intrarregionales y se volvió a analizar y discutir las propuestas presentadas por Uruguay, Ecuador y Argentina. En dicha reunión los Estados Miembros de la Unión volvieron a reconocer "la libre movilidad y las facilidades de residencia dentro de la región como elementos esenciales para la construcción de la identidad y la ciudadanía suramericana”, así como considerar que esta última "debe ser un proceso dinámico, progresivo y gradual” (Unasur, 2015b).

Entre las acciones acordadas en esa reunión se puede señalar el avance en la elaboración del Plan de acción y trabajar en cuatro ejes: simplificación administrativa, modernización tecnológica, perspectiva de derechos y asistencia y protección consular. En relación al primer eje, se habló de promover procesos de regularización, eliminación de medios de vida para solicitar residencia permanente, reducción progresiva de costos y proponer la elaboración de un Acuerdo de Residencia Unasur que contemple la simplificación de los requisitos para su obtención.

16 En diciembre del 2014 se inauguró la sede de Unasur en la Mitad del Mundo (Ecuador), donde funciona la Secretaria General (SG). En ese año, ya con Ernesto Samper a la cabeza, se inicia un proceso acelerado de institucionalización conformando las diferentes direcciones y unidades de apoyo. 
En varias instancias se habla de construir un mecanismo que facilite la libre movilidad de los suramericanos o elaborar un Acuerdo de Residencia Unasur tal como quedó en el informe de la última reunión presencial del GTCS realizado en junio del 2016 en la ciudad de Quito donde se señaló que los avances en materia migratoria “conducen al cumplimiento del objetivo mayor que es lograr un Acuerdo de Residencia Unasur" (Unasur, 2016b:3).

Para impulsar este tema, que constituye parte medular del trabajo de la Secretaría General de Unasur en estos dos últimos años, se elaboraron dos documentos donde se marca los principios, aspectos teóricos cuantitativos y la propuesta política: "Hacia el Sur: La construcción de la ciudadanía suramericana y la movilidad intrarregional" y el "Plan de Acción integral de ciudadanía suramericana: movilidad, identidad y derechos" que constan en una reciente publicación de Unasur (2016a).

Dicho Plan fue presentado como iniciativa de la Secretaría General de Unasur en la última reunión cancilleres de abril del $2016^{17}$ y contempla 5 ejes: migración y protección diplomática y consular; movilidad académica; migración forzosa; identidad y cultura; trabajo y seguridad social y, participación ciudadana.

Como se observa existe la voluntad política, una reflexión teórica necesaria y un recorrido a nivel subregional importante que permiten caminar hacia una plena ciudadanía suramericana. Unasur, en el redimensionamiento de la ciudadanía en el plano regional se plantea nuevos desafíos y miradas. Además, establece como primera dimensión la migratoria, pero continúa con las otras dimensiones ya señaladas las cuales se han empezado a discutir y trabajar en los diferentes Consejos Sectoriales ${ }^{18}$ en el marco de sus planes operativos quinquenales.

17 Reunión que tenía que ser de Jefes y Jefas de Estado pero por motivos del terremoto que afectó a Ecuador no se pudo realizar.

18 Tales como el Consejo Suramericano de Educación, Consejo de Cultura, Consejo de Desarrollo Social, Consejo suramericano de Ciencia, Tecnología e Innovación, Consejo se materia de Seguridad Ciudadana y Justica. 


\section{Conclusiones}

Se puede constatar un largo recorrido en la región para construir un proceso de integración donde los temas migratorios han estado presentes, desde aquellas miradas que veían y ven la movilidad solamente como mano de obra de trabajadores, hasta las actuales propuestas de construir una ciudadanía suramericana.

La CAN y Mercosur, cuya centralidad ha estado en las preocupaciones económicas y comerciales, han dado a la movilidad un carácter sobre todo laboral y no han podido desvincularse de las perspectivas securitistas o utilitaristas como se pude ver en varias de sus decisiones o acuerdos. De todos modos hay que reconocer los avances dentro de estos espacios, sobre todo con la creación del Acuerdo de Residencia Mercosur que permite temporalmente residir sin necesidad de tener un contrato laboral.

Mientras que la Unasur, en cuyo seno están los intereses sociopolíticos de la región y donde todos los países son miembros plenos, ha entendido la movilidad humana desde un enfoque multidimensional y multisectorial, apostando en un primer nivel no sólo a la libre movilidad en la región, sino sobre todo a las facilidades de residencia que permita el ejercicio pleno de los derechos de las personas de la región. De ahí el impulso al proyecto de ciudadanía suramericana que ya está en la agenda intergubernamental de los Estados miembros de la Unión.

Vale la pena resaltar que en el ámbito de Unasur, los 12 jefes y jefas de Estado aprobaron un concepto, una definición por consenso sobre ciudadanía suramericana no solo circunscrita al ámbito político jurídico, sino también al socio cultural. Dicha definición constituye la piedra angular para todo el camino recorrido y el que viene por delante. Como se sabe, las decisiones tomadas en los espacios multilaterales se cocinan a fuego lento y toman tiempo en implementarse. Sin embargo, se tiene que entender que la propuesta de ciudadanía suramericana es un proceso gradual en el cual ya se han dado varios pasos dentro de la región como son: libre movilidad intrarregional (todos los ciudadanos podemos movernos e ingresar a la mayoría de países de la región con la sola presentación del documento nacional 
de identificación, sin necesidad de visas ni pasaportes); existen facilidades para la residencia temporal, reconocimiento de ciertos derechos civiles, sociales y políticos en varios países, entre otros. Pero el objetivo final es tener un nuevo instrumento o Acuerdo que se ha denominado Acuerdo Unasur de libre movilidad, residencia y ciudadanía suramerciana (Ramírez, 2016). Vale la pena señalar que algunos países como Ecuador, de manera unilateral, están acogiendo la propuesta de ciudadanía suramericana para incoorporar en su marco normativo que está en construcción dentro de la Asamblea Nacional.

El reto de los acuerdos de integración que tengan que ver con la temática de la movilidad humana está en aprender de las experiencias pasadas y entender que el ejericio de la ciudadanía no debe estar supeditado a intereses económicos ni necesidades mercantiles de los países miembros. De igual manera es necesario superar los enfoques de seguridad y control -lastimosamente aún vigente no solo en la región sino en el mundo para dejar de ver al migrante como un problema, una amenaza o una mano de obra ya sea neoesclava, barata o calificada. Los vientos que soplan en la región con el retorno de un regionalismo abierto en algunos países pueden obstaculizar y retroceder lo construido en esta materia en los últimos años.

De ahí la importancia de que espacios como Unasur, los Gobiernos progresistas y la sociedad civil acompañen y empujen la propuesta de la ciudadanía suramericana que permitirá acabar con la constante vulneración de los derechos, las expresiones xenófobas y la exacerbación de las desigualdades sociales entre nacionales y extranjeros. Esto implica pasar de políticas de hostilidad a políticas de hospitalidad, además de dejar de ver a los extranjeros como 'otros' y reconocerles como parte de la polis local, nacional y regional.

\section{Bibliografía}

Alonso, A. (2012). Integración y migraciones. El tratamiento de la variable migratoria en el Mercosur y su incidencia en la política argentina. Buenos Aires: Organización Internacional del as Migraciones. 
Anderson, B. (1993) Comunidades imaginadas. México: Fondo de Cultura Económica.

CAN (s/f) (en línea). Decisiones de la Comunidad Andina de Naciones (Fecha de consulta: septiembre 2015) Disponible en: http:/www.comunidadandina.org/Normativa.aspx? GruDoc $=07$

CAN (2008). “Acta del Primero Foro Andino de Migraciones”. Quito: CAN.

CAN (2015). "Propuesta de Estauto Andino de Movilidad Humana. Parlamento Andino". Quito: Oficina Nacional Ecuador.

Mercosur (1994) (en línea). "Protocolo de Ouro Petro". (Fecha de consulta: 16 de abril de 2016). Disponible en: http://www.mercosur.int/innovaportal/ file/721/1/cmc_1994_protocolo_ouro_preto_es.pdf

Mercosur (1998) (en línea). “Declaración Sociolaboral del Mercosur”. (Fecha de consulta: 16 de abril de 2016) Disponible en: http://www.sice.oas.org/ labor/MERCOSUR_Sociolab.pdf

Mercosur (2010) (en línea). “Estatuto de la ciudadanía del Mercosur. Plan de Acción”. (Fecha de consulta: 14 de abril de 2016). Disponible en: http:// www.srt.gob.ar/images/pdf/mercosur/DEC_064-2010_ES_Estatuto_de_ Ciudadania.pdf

Modolo, V. (2012). "Política migratoria regional. El caso de la Residencia Mercosur 2002-2011”. En Revista Aportes para la Integración Latinoamericna pp.40-58.

Ramírez, J. (2012). Ciudad-Estado, inmigración y políticas. Ecuador 1980:1950. Quito: Instituto de la Ciudad-IAEN.

Ramírez, J. (2016). Hacia el Sur. La construcción de la ciudadanía suramericana y la movilidad intrarregional. Quito: CELAG.

Rojas, F., Altmann J., Beiture, T. (2012) “Integración política: un camino hacia la integración latinoamericana”. En Altmann (ed.) América Latina: caminos a la integración regional. San José: Flacso-CAF.

Stang, M.F. (2009). "El migrante unidimensional. El disposititvo jurídico migratorio de la Comunidad Andina de Naciones". En Domenech, E. (comp.) Migración y política: el Estado Interrogado. Córdoba: Universidad Nacional de Córdoba.

Unasur (2008). “Tratado Constitutivo de la Unión de Naciones Suramericanas”, entrada en vigor 2011. Quito: Secretaría General.

Unasur (2014a) "Declaración reunión Extraordinaria del Consejo de Jefas y Jefes de Estado y de Gobierno de Unasur” Buenos Aires: Unasur. 
Unasur (2014b) (en línea). "Informe Conceptual sobre Ciudadanía Suramericana". (Fecha de consulta: 15 de septiembre de 2015). Disponible en: www.amerindiaenlared.org/.../ informe-conceptual-sobre-ciudadania-suramericana

Unasur (2014c). "De la visión a la acción”. Iniciativas presentadas por la Secretaría General a la consideración de la Cumbre Extraordinaria de Unasur que se celebrará en Ecuador los días 4 y 5 de diciembre del 2014. Santa Cruz: Unasur.

Unasur (2015a) "Resumen de la Video Conferencia del Grupo de Trabajo de Ciudadanía Suramericana, del 3 de septiembre del 2015”. Caracas: Unasur.

Unasur (2015b) "Informe de la Reunión Presencial del Grupo de Trabajo de Ciudadanía Suramericana, Montevideo 24 y 25 de noviembre del 2015". Montevideo: Unasur.

Unasur (2016a) "Hacia el sur. La constricción de la ciudadanía suramericana y la movilidad intrarregional”. Serie Birácaras No. 2 Mitad del Mundo.

Unasur (2016b) "Informe de la reunión presencial del Grupo de Trabajo de Ciudadanía Suramericana.” 28 y 29 de junio del 2016, Mitad del mundo. 